This item was submitted to Loughborough's Research Repository by the author.

Items in Figshare are protected by copyright, with all rights reserved, unless otherwise indicated.

\title{
Evaluating business simulation software: approach, tools and pedagogy
}

PLEASE CITE THE PUBLISHED VERSION

PUBLISHER

(C) Emerald Group Publishing Limited

VERSION

AM (Accepted Manuscript)

LICENCE

CC BY-NC-ND 4.0

REPOSITORY RECORD

King, Melanie R.N., and Richard Newman. 2019. "Evaluating Business Simulation Software: Approach, Tools and Pedagogy". figshare. https://hdl.handle.net/2134/5403. 
This item was submitted to Loughborough's Institutional Repository (https://dspace.lboro.ac.uk/) by the author and is made available under the following Creative Commons Licence conditions.

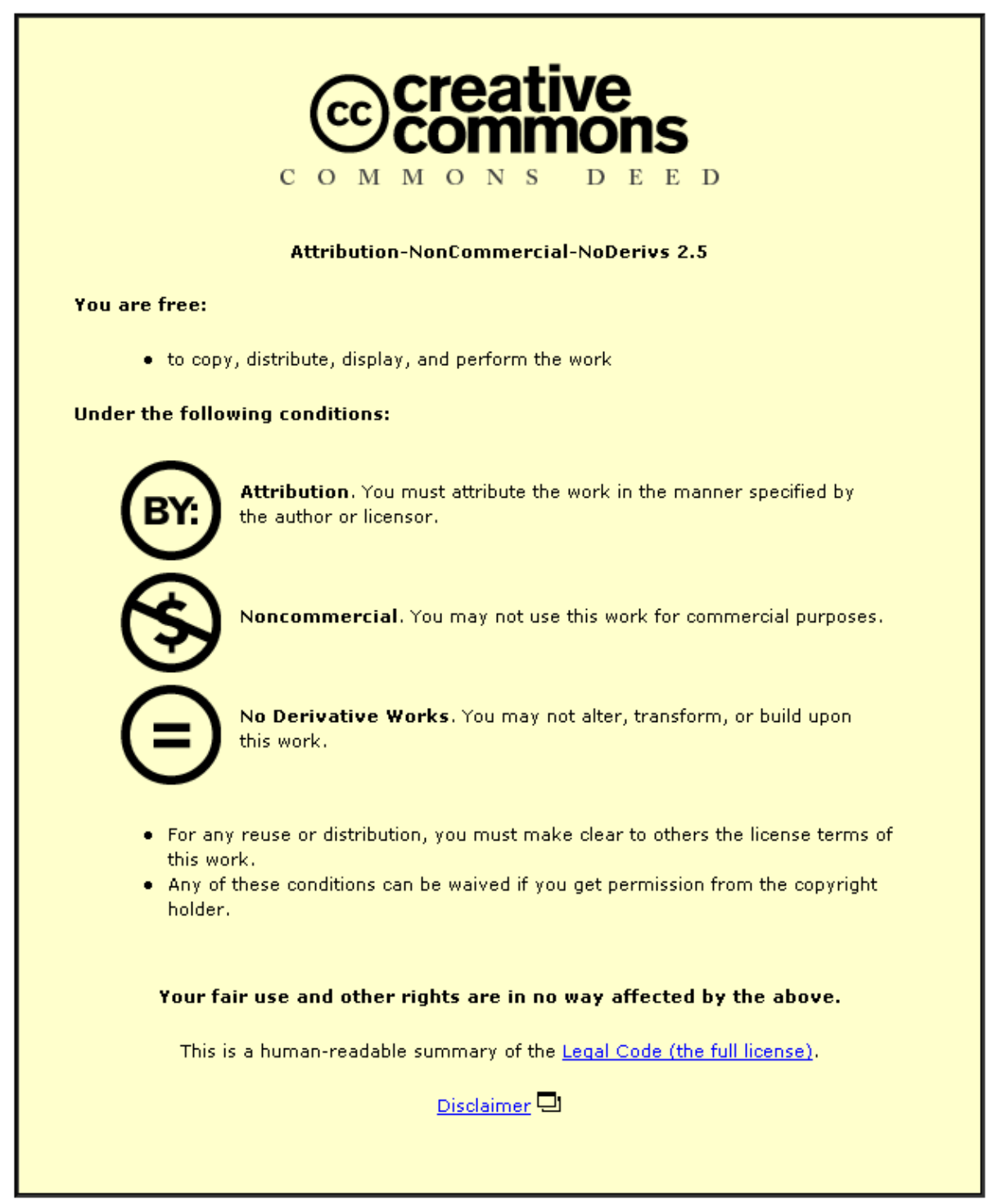

For the full text of this licence, please go to: http://creativecommons.org/licenses/by-nc-nd/2.5/ 


\title{
EVALUATING BUSINESS SIMULATION SOFTWARE: APPROACH, TOOLS AND PEDAGOGY
}

\author{
Melanie King and Richard Newman \\ engCETL (Engineering Centre for Excellence in Teaching \& Learning), \\ Loughborough University, Loughborough, UK
}

\begin{abstract}
Purpose - To identify a business simulation appropriate for MEng Engineering students. The selection was based on the following factors; exploring methods for evaluating potential software and enhancing the learner experience.

Design/methodology/approach - An interdisciplinary project team was formed to try and resolve the pedagogic, technical and business aspects that would need to be addressed in order to implement such software within the programme. Tools included a questionnaire to assess the potential enhancement of employability skills and a usability questionnaire on ease of use. These were supplemented with discourse on technical and pedagogic issues.

Findings - After the initial scoping study, our findings indicated that two business simulation software packages had potential. These were 'Marketplace Venture Strategy' and 'SimVenture'. Marketplace proved to be the most suitable in terms of the pedagogic and technical requirements.

Research limitations / implications - We were not able to fully trial each simulation over the recommended duration of play because of practical time constraints and we did not have any student contribution to the process. Findings will need to be verified with the piloting cohort of students. Further pedagogic research could be carried out to evidence the enhancement to the student learning experience.

Originality/value - This study is valuable because it purposefully uses an interdisciplinary team comprising expertise in; teaching and learning, technology, business and sector knowledge. This was vital in the decision making process. Development of generic methods and tools to measure and evaluate software suitability in relation to usability and employability skills.
\end{abstract}

Keywords Software, Simulation, Employability, Skills, E-Learning, Usability

Paper type Research 


\section{INTRODUCTION}

There is a drive within engineering disciplines at Loughborough University to develop the employability skills of undergraduate students. The engCETL (Engineering Centre for Excellence in Teaching \& Learning) has a broad remit to enhance links with industry and to underpin developments in learning and teaching with pedagogic research and technology solutions. The Centre does this through research and development projects that are proposed by academics within the engineering related departments and carried out in conjunction with specialists from the engCETL team.

The Head of Department of Aeronautical and Automotive Engineering proposed the project in April 2007. The deliverable he required as an output was some form of business simulation software for use in the Year 4 (Part D) Management module but that could also potentially be transferable to other departments.

There are currently two Year 3 (Part C) management modules, in which students produce a business plan and end the assessment with a presentation to a panel, similar to the television programme "Dragons' Den." However, there was a desire within the department to investigate the introduction of a Year 4 Management module, for the students to continue their business plan through an interface with a virtual business. The intention of introducing this would be to enliven and enrich the students' learning experience with skills development such as; enterprise, leadership, management, teamwork, fiscal sense, business judgment and inventiveness. Furthermore, The Royal Aeronautical Society (RAeS) and the Institution of Mechanical Engineers (IMechE) accredit the Aeronautical and Automotive Engineering degrees and it is a requirement of them to teach Management skills. The introduction of the Year 4 Management module would therefore help to validate the Professional Bodies' accreditation.

The project did not intend to develop a bespoke software simulation in-house but instead conduct a scoping study to investigate what business simulation software was available. We carried out a literature search in the area including examples of where simulation or business concepts have been taught within higher education. The investigation analysed the simulations in the context of the Aeronautical and Automotive Management module requirements. The initial scoping study made recommendations for an in-depth evaluation of two simulations.

This particular study and associated research is important because it aims to address three of the top ten teaching and learning issues identified by Campbell (2007) for the EDUCAUSE Advisory Committee for Teaching and Learning $(A C T L)$ :

- Selecting appropriate models and strategies for e-learning

- Providing tools to meet growing student expectations

- Understanding the evolving role of academic technologists.

To address the first of these issues, the project set out to pilot an appropriate model to evaluate software for use in teaching and learning. To address the second issue, of selecting the appropriate tools, the project focused on the business simulation software and complimentary tools. To inform the growing 
body of knowledge on the evolving role of academic technologists and subject specialists, the research set out to capture the different and varied roles of an inter-disciplinary project team.

This research is also important as it addresses the implications highlighted in a study of the effectiveness of Management Simulations (Adobor and Daneshfar, 2006). They initially carried out the evaluation with students but advocated the role of the instructor or tutor in taking an active role in the process.

The Project team incorporated expertise from a number of disciplines and industrial viewpoints. This approach was used to jointly investigate and advise on the broad areas that needed investigation, such as pedagogy, technology, employability skills and evaluation. The project team comprised; Head of Department, External Tutor, Industrial Liaison Officer, two Business Consultants from Accenture (http://www.accenture.com), Academic Technologist and a Research Assistant.

\section{SCOPING STUDY}

From initial meetings, the following requirements were discussed in relation to potential simulation software. The simulation needed:

- to be comprehensive and the student must be in control of the data entered

- to provide detailed and up-to-date information but perhaps the students can go in and manipulate some of this data

- to simulate sudden changes in the market and the students could be rewarded for reacting to these

- a time dimension and random real-world interventions

- to simulate several years of being in business during the Semester

- to have 'random noise' in the information across groups.

After an initial meeting and exploratory look at the commercial and open source software, a shortlist was compiled for further in-depth evaluation. For addition to the shortlist, the commercial and open source software were initially compared in terms of; price, staff demands, fixed/variable industry, learning outcomes, trading style, number of players, playing style and target student audience.

Attributes recommended from the literature where also considered as very important when considering potential simulations. Oblinger (2004), states that, "Games have many attributes of effective learning environments. For example, games include elements of urgency, complexity, learning by trial-and-error and scoring points. They also support active learning, experiential learning and problem-based learning. Games make it possible to use information in context and are inherently learner-centered and provide immediate feedback."

A search for open source options from 'Sourceforge.net' (http://sourceforge.net) using the search terms 'business + simulation' and 'business + game' came up with eight results. Four of these projects had a $>70 \%$ activity ranking and had recorded some downloads, shown in Table I. 
Table I: Open source business simulation software

\begin{tabular}{|l|l|c|c|c|}
\hline Name & Description & Activity & Latest File & Downloads \\
\hline Pizza Business & $\begin{array}{l}\text { Start up and control of } \\
\text { a pizza restaurant. }\end{array}$ & $95.19 \%$ & $04-05-02$ & 15,235 \\
\hline Free Train & $\begin{array}{l}\text { A rail and business } \\
\text { simulation inspired by } \\
\text { the A-Train series. }\end{array}$ & $98.69 \%$ & $07-02-07$ & 4,061 \\
\hline WiSim & $\begin{array}{l}\text { Simulates the task } \\
\text { scope and complex } \\
\text { processes of a hub } \\
\text { producing company. }\end{array}$ & $93.30 \%$ & $26-05-03$ & 1,392 \\
\hline CadaWeb & $\begin{array}{l}\text { A business game to } \\
\text { teach students how the } \\
\text { economy works. }\end{array}$ & $71.08 \%$ & $16-10-04$ & 271 \\
\hline
\end{tabular}

From a review of the literature, specific business simulations to support Aeronautical and Automotive students were not apparent. However, successful examples of using business simulations in Higher Education, both in the UK and in the USA, were found. In a case study, from the Higher Education Academy Business, Management and Accountancy Subject Centre, Peters and Brodie (2005) reported on the use of 'Marketplace' (http://www.marketplacesimulation.co.uk) in a range of taught Masters in the field of business, management and marketing at the University of East Anglia, UK. Results from the piloting of Marketplace were positive showing that, "The teaching team for the UEA MSc programme has found the introduction of Marketplace Business Simulation of great importance in helping our students to gain a real 'feel' for managerial decision-making and teamwork". An example of the use of a business simulation in the USA was reported by Ben-Zvi and Carton (2007). They discussed their experiences of using 'Intopia' within the MBA at the Wesley J. Howe School of Technology Management, Hoboken, N.J. USA.

An Internet search using Google revealed many results but in particular 'SimVenture' (http://www.simventure.co.uk), predominantly aimed at the schools and colleges market, won the BETT 2008 educational technology award in the 'Post-16 Education and Training' category.

From the scoping study two commercial options were short-listed for further detailed evaluation, these were Marketplace Venture Strategy and SimVenture. Intopia was ruled out at this stage, although having many sophisticated and similar features to Marketplace, it required a trained facilitator to run the game. It was also felt that the Open Source options were not appropriate because they were too specialised or related to specific industries, not recent enough or were using a technology that IT staff at Loughborough had no expertise in. 


\section{METHODOLOGY}

Adobor and Daneshfar (2006), when determining the effectiveness of management simulations, developed measures to assess factors in three main areas. These are; team dynamic factors (emotional and task conflict), userfriendliness and realism of the simulation. The project team used these factors as a starting point. To address the team dynamic factors we used a questionnaire to assess employability skills including team working, communication and dealing with conflict. The second factor of user-friendliness was addressed by a questionnaire relating to the usability of the simulation using recognised methods and the third factor, involving realism, would be addressed by including experienced business consultants and a lecturer with experience in industry in the project team who was integral to the evaluation, assessing the realism of the simulation.

The project team split into two groups (6 respondents in total) to evaluate each simulation, with three individuals evaluating both simulations. The intention was to carry out the simulation as a group of students would, taking notes on how we found using the software initially, detailing; time spent on tasks, logistics of using the software as a group (some of whom were based in different locations) and our general initial impressions. More formal evaluation including; pedagogic, technical and usability evaluation, would be carried out and would allow us to gain more quantitative data for each simulation. Consideration of the logistics of implementing each simulation within the IT infrastructure of the University was made.

To address a more formal pedagogic evaluation, we focused on the employability skills for students that the software might have a positive impact upon. The skills portfolio list and descriptions taken from the publication, 'The Art of Building Windmills - Career tactics for the 21st Century', Hawkins (1999). Peter Hawkins is the co-founder and adviser to the Graduate Into Employment Unit at the University of Liverpool.

Graduate Prospects (http://www.prospects.ac.uk), the UK's official graduate careers website, also use the Windmills skills portfolio list to highlight the skills that employers want. For the purposes of the questionnaire 18 distinct skills would be used to measure perceptions of how the students would develop each of these through using the business simulation software. The 18 skills are categorised as either people skills (teamworking, leadership, interpersonal skills, customer orientation, oral communication and foreign language), self-reliance skills (self-awareness/confidence, self-promotion skills, initiative and proactivity, networking skills, willing to learn and action planning) or generalist skills (problem-solving, IT/computer literacy, flexibility, numeracy skills, business acumen and commitment). Respondents were asked, "if a team of students used the business simulation software, to what extent would you anticipate that the experience would have a positive impact on their employability skills?" Each individual skill was on a scale of 0 to 10 ; a score of 0 being, "having no impact" and a score of 10 , "having a high impact".

The technical evaluation addressed the issues relating to; purchasing, using, maintaining and supporting the software within the University network. This was 
carried out by the Academic Technologist and was broken down into statements on; maintainability, extendibility, robustness (reliability), compatibility and accessibility.

All members of the project team carried out the usability evaluation. This involved a series of 20 statements based on the 10 Heuristic principles (Nielsen, 2005). These statements covered aspects of; visibility of system status, match between system and the real world, user control and freedom, consistency and standards, error prevention, recognition rather than recall, flexibility and efficiency of use, aesthetic and minimalist design, help users recognize, diagnose and recover from errors and help and documentation. The questionnaire used a Likert scale where respondents indicated an opinion on each statement for both Marketplace and SimVenture with one of the following; strongly disagree, disagree, no opinion, agree or strongly agree.

The usability questionnaire and employability questionnaires were sent via email to the six people that used Marketplace and the five that used SimVenture. Five people completed the questionnaires regarding Marketplace and three people completed the questionnaires regarding SimVenture. All questionnaires were completed independently.

\section{USER EVALUATION}

The employability skills questionnaire provided us with some very useful quantitative data that could easily be compared between each application. Averages were made for each skill and generally all respondents were in close agreement on the rating against each skill. Exceptions to this were the scores for customer orientation and foreign language for Marketplace where scores ranged from 2 to 7 and 0 to 7 respectively.

For Marketplace and SimVenture, business acumen was the employability skill that the respondents felt would achieve the highest positive impact on the students. This was expected, as this is one of the main purposes of the simulations. Marketplace scored very highly on team working skills closely followed by interpersonal, action planning and leadership skills. Initiative, proactivity and action planning scored highly for SimVenture. SimVenture had a very low average for foreign language and both Marketplace and SimVenture had a low average for customer orientation. Figure I shows results for Marketplace and Figure II shows results for SimVenture. 
Figure I

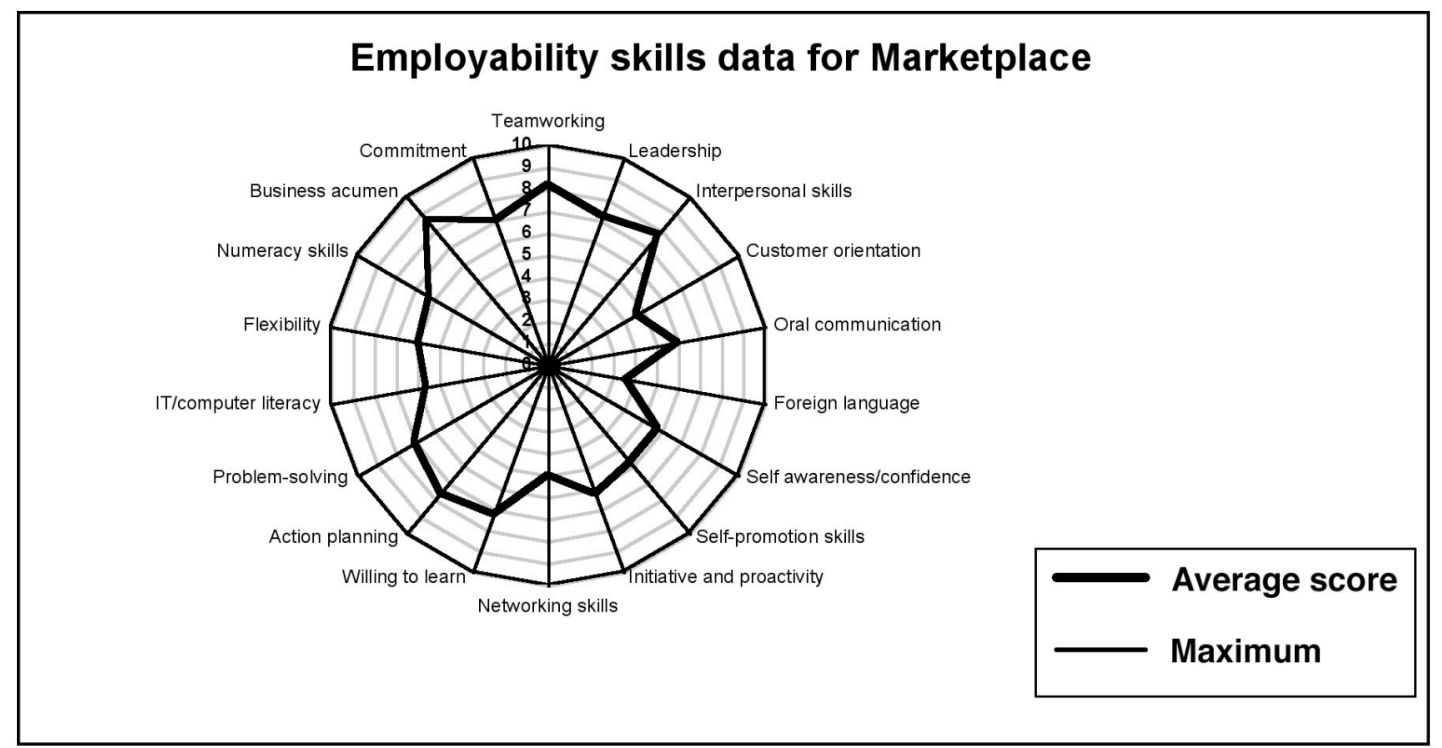

Figure II

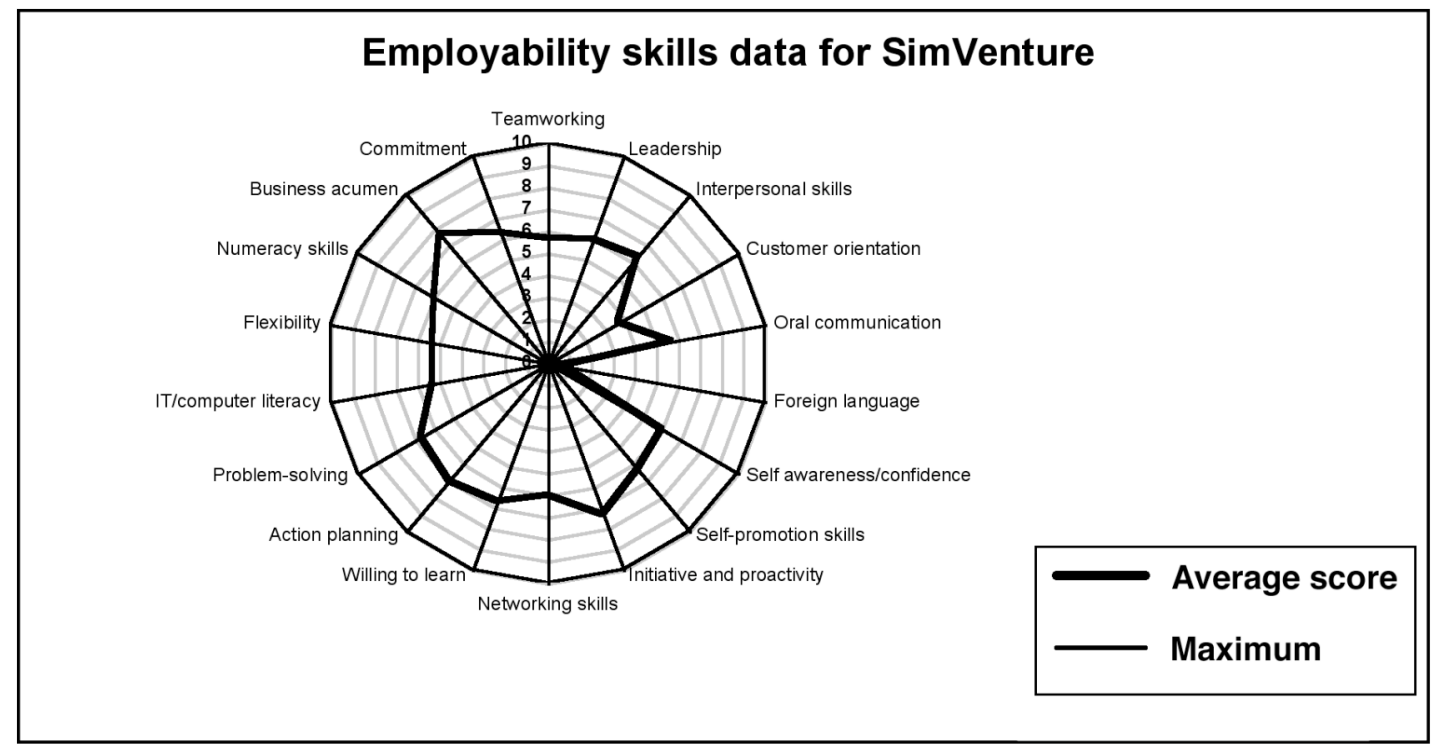

Hawkins groups the skills into categories including; People Skills (teamworking, leadership, inter-personal skills, customer orientation, oral communication and foreign language), Self-reliance Skills (self-awareness/confidence, self-promotion skills, initiative and proactivity, networking skills, willing to learn and action planning) and Generalist Skills (problem-solving, IT/computer literacy, flexibility, numeracy skills, business acumen and commitment). Adding the averages for each skill within these three categories, the two simulations can be rated as follows. 
Out of a maximum score in each category of 60 , Marketplace scored slightly higher (40.4) for generalist skills compared to SimVenture (37.33). However, for self-reliance skills, SimVenture scored slightly higher (39.33) compared to Marketplace (37.6). The greatest difference in scoring was for people skills where respondents scored Marketplace (37.4) compared to SimVenture (28.01). The higher scores for SimVenture for self-reliance skills might be expected because the simulation is aimed at those who would like to start-up and run a virtual company.

Overall, Marketplace scored the highest (115.4) compared to SimVenture (104.67) out of a possible maximum score (180) indicating that Marketplace should have the greatest positive impact on the employability skills of students, particularly for generalist skills, which includes business acumen.

\section{TECHNICAL EVALUATION}

The technical evaluation reported on comparisons for; maintainability (the ease at which upgrades, updates, maintenance of licences, application of patches and associated costs), extendibility (the ease with which a software system can be modified to change or add capabilities, improve performance or correct defects), robustness or reliability (a system that does not easily break down, either recovers quickly from or holds up well under exceptional circumstances), compatibility (the way in which the system interacts with existing operating systems, software and hardware needed) and accessibility (the compliance to regulations of accessible software, for example, the Special Educational Needs and Disability Act 2001 (SENDA) requirements).

The additional resources needed to maintain SimVenture would be significantly higher because it is a desktop application that would need to be installed on individual PC's, use an internal networked licence server and require that University staff update, upgrade and patch the installation. Marketplace is hosted remotely on the Internet and maintenance is the responsibility of the commercial provider, Innovative Learning Solutions.

A costing for each simulation was obtained and compare as follows. Marketplace Venture Strategy would cost $£ 20.50$ per student playing against peer teams in the same simulation, the total cost for 80 students being $£ 1640$. This cost would be paid every academic year on a recurrent basis. SimVenture costs $£ 120$ per individual licence for a PC and up to 4 students could use the software on the PC as a team. The cost for 80 students is $£ 2400$ (20 groups with 4 students in each group). SimVenture apply a $15 \%$ discount on orders of 16 or more licences, with the discount only applying to the 16th order and above, so the total cost is $£ 2310$ ( $£ 90$ discount on 5 licences). Maintenance, support and basic software upgrades for 12 months are included. After 12 months upgrades can be purchased for SimVenture. All costs exclude VAT and are for the 2007/08 academic year.

Extendibility was explored to see if any tailoring of the content of the simulation could take place. Each simulation is based on a fixed scenario and cannot be changed by the end-user. However, quotes were obtained from each company to create bespoke simulations and were prohibitively expensive for Marketplace 
but could perhaps be a possibility for SimVenture. Both Marketplace and SimVenture proved to be reliable and robust within our evaluation.

It was felt that Marketplace would be more compatible and accessible to a wider group of users because SimVenture requires a PC with a specific operating system, whilst Marketplace will run through most Internet browsers with JavaScript and cookies enabled. Also, SimVenture requires a group of students to carry out the simulation on the same PC at the same time, in comparison to Marketplace where each student can log-in from different computers at different times.

The results of the usability questionnaire showed that respondents were in general agreement for each statement. In general Marketplace had more positive results for statements on usability compared with SimVenture. There are 3 principles in which the two simulations significantly differed, these were; visibility of system status, user control and freedom, and error prevention.

All respondents agreed or strongly agreed that Marketplace, "..always kept me informed about what was going on and what stage I had reached in the game with status information, appropriate feedback and/or timely instructions", whereas all respondents disagreed with this statement for SimVenture. All respondents disagreed that within Marketplace they, "..often needed to cancel or undo actions that were clicked by mistake", whereas all of the SimVenture respondents agreed with this statement. All respondents agreed or strongly agreed that the Marketplace simulation, "..provided the opportunity to enter data and change it to 'play' with different outcomes before committing", whereas those who used SimVenture disagreed or strongly disagreed with this statement.

\section{FINDINGS: CHOICE OF SOFTWARE}

Our recommendations were that Marketplace would be the most appropriate business simulation software that could be integrated into the Management module. This simulation software could be integrated in to any other module that had the same requirements, as the content is generic enough to suit different subjects. This recommendation comes from the evidence provided within the employability, usability, pedagogic and technical evaluations as well as statements from the respondents on general impressions of using the simulations.

General impressions of Marketplace, from the group as a whole, were mainly positive. It initiated a lot of good discussion and debate between the project team, involved a wide range of important business subjects and it is structured and methodical in its delivery. The software would not allow you to wrap up any decision round without taking all the actions that are necessary in that quarter, or move on without saving your actions, which was very helpful considering how many decisions there were to make and, potentially, to forget to save. Pop-up wisdom screens explain the effect of some types of decision and action, putting the various possible actions and business considerations in context, which may prove particularly illuminating for the newcomer to business thinking. Once over our initial skepticism, we found the process of going through the business decisions to be fun, engaging and challenging to our preconceived ideas. We 
warmed very quickly to the software and what at first was considered to be weaknesses, in terms of plain forms and dense text, soon became real benefits as we searched for reasons why we should or should not take certain decisions. In fact, after only one decision round we found ourselves caring about the virtual business we started just over an hour and a half earlier.

Results from the usability study and technical investigation favoured Marketplace and it also scored the highest within the employability skills evaluation. Marketplace would be more appropriate for incorporating into the curriculum with regards to flexibility of use for individual students and teams. A real benefit also, is the detailed log that is kept of each student's interaction with the simulation in relation to time spent and decisions made, which will provide the tutor with a better overview of the progression through the simulation. Marketplace is also more appropriate for the programme level and required learning outcomes for the Management module as opposed to SimVenture, which we felt might be more suited to ad hoc individual use. It would be a useful trial however, for a small number of SimVenture licenses to be made available on PC's or laptops for interested students to practice setting up and running a virtual business.

The initial cost of Marketplace is significantly less than SimVenture and even though Marketplace will have the same yearly costs whilst SimVenture will not, we felt that this might be outweighed by the institutional cost of the installing, maintaining and upgrading SimVenture on a yearly basis.

\section{RECOMMENDATIONS FOR ENHANCING THE LEARNER EXPERIENCE}

General recommendations, for embedding the Marketplace business simulation into the curriculum, can be made based on general blended learning pedagogic theory. These recommendations include the range of support, direction and monitoring of team and individual performance that the instructor can provide, aided by face-to-face tutorials supplemented with information, learning and communication technologies.

Recommendations from the Adobor and Daneshfar (2006) study include the need to pay attention to team dynamics as well as the importance of defining the distinct learning outcomes for individuals as opposed to the objectives for the teams. They also recommend that the ongoing involvement of the game administrator or instructor is integral. The simulation supports the monitoring of individual and team performance with the use of very detailed reports that can be accessed by the instructor. It will be important to explain this to the students so that they understand they each have a role to play within the virtual corporation and therefore responsibilities for certain decision making within each team.

In relation to the issue of team dynamics, there is an obvious need for the students within a team to be able to collaborate not only face-to-face but remotely. The formal contact time for the instructor and students is planned for a preparation lecture in week 1 , team tutorials in week 6 (half way through the simulation) and then after the simulation has finished for final presentations. Therefore the majority of the team meetings will be away from the instructor and probably remotely from each other. The students will need to make in-depth 
decisions on tactics, strategy and the actual inputting of the data for each round of the simulation. There is potential for conflict and mistakes to be made early on in the teams, so tools for online private discussion will be required that can also be accessed by the instructor. These private discussions areas are not provided within the simulation itself but can be created within the University's Virtual Learning Environment (VLE).

The requirement for the student face-to-face and online collaboration is intended to not only help the instructor monitor team dynamics but should also enhance the learner experience. Garrison (2004) reports on the wider literature supporting the potential of technology to create more meaningful educational experiences, "... asynchronous computer-mediated conferencing supports flexibility, reflection, interpersonal and teamwork skill development, motivation, and collaborative learning environments - resulting in deep and meaningful understandings and communities of inquiry". Furthermore, online forums can provide a permanent record of thinking and discourse between team members which is often more thoughtful, reasoned, and supported by evidential sources (Meyer, 2003).

To address the need for individual learning outcomes that are distinct from the overall objective of the team to win the game, an individual reflective diary per student, based on their experience of using the business simulation is recommended. This might include their initial input to the original business plan, their role within the virtual company, decisions and involvement in the team as a whole and what they learned from the experience of running their virtual corporation.

The Marketplace simulation provides each virtual corporation with a 'balanced scorecard' indicator of their performance as a company. The 'balanced scorecard' (Kaplan, 1992), is a set of performance measures that gives a view of the business including; financial performance, operations, customer satisfaction, internal processes, innovation and learning perspective. The 'balanced scorecard' for each team could be incorporated into the final group mark.

An individual assessment could be made using a peer-moderated marking system of each student's contribution to the team as a whole. The peer assessment system WebPA is recommended (http://www.webpaproject.com) to help achieve a grade for each student in relation to the group mark given. Loddington (2008) reports on a study showing the benefits that this system provides for the tutor as well as enhancing the learning experience of the students. It provides each student with the opportunity to rate the contribution of each of their team members and a chance for self-reflection on their own performance.

\section{CONCLUSION}

The objectives of the project were to select an appropriate strategy to evaluate potential business simulation software and provide the best simulation to meet the learning objectives of the module. Furthermore, it was to recommend additional tools to enhance the student learning experience by taking a blended approach to team and tutor collaboration coupled with assessment of the 
simulation and individual performance, and to meet growing student expectations of technology enhanced learning. It was also to understand what benefits there might be of having a project team comprising specialists and industrialists working together with a course team to help evaluate and re-design a curriculum set around a business simulation.

Overall, we have found the quantitative methods used to capture the usability and employability skills data to be quick and effective. They gave the team a rich insight into the strengths and weaknesses of each simulation and provided the opportunity to thoroughly compare each simulation and their suitability for the module. These tools are generic and could be easily used by others in aiding a decision making process for evaluating learning technology in general.

We strongly advocate an inter-disciplinary team approach in the selection, evaluation and recommendations for curriculum design when considering using a simulation within your teaching. It not only gave the team valuable insights into the realism of the software, academic content and suitability for use at the programme level but gave the instructors a useful awareness of the logistical and technical implications for each simulation. It also enabled the opportunity to incorporate grounded pedagogic theory into the recommendations on using a blended learning approach to the curriculum design and helped to recommend additional learning technologies that will enhance the overall learning experience.

The research had some limitations. As a project team we were not able to fully trial each simulation over the recommended duration of play because of practical time constraints. We did not have any student contributions to the process, so findings will need to be verified with the cohort of students who will be piloting the game and more in-depth pedagogic research will need to be carried out to evidence the enhancement to the student learning experience using the recommendations for a blended approach.

Finally, the logistics of piloting the Marketplace simulation with a cohort of 80 students will need to be closely monitored. The number of students will necessitate running two parallel simulations because each simulation will only allow approximately 8 teams to play comprising of up to 6 team members in each. The potential market will be driven by the decisions of each corporation within each game; therefore students may experience different scenarios and learning experiences, based on the strategies of their competitors.

\section{REFERENCES}

Adobor, H. and Daneshfar, A. (2006), "Management simulations: determining their effectiveness", Journal of Management Development, Vol. 25, No. 2. pp. 151-168.

DOI: $10.1108 / 02621710610645135$.

Ben-Zvi, T. and Carton, T.C. (2007), "From Rhetoric to Reality: Business Games as Educational Tools," INFORMS Transactions on Education, Vol. 8, No. 1, pp. 1018. 
Campbell, J.P., Oblinger, D.G. et al. (2007), "Top-Ten Teaching and Learning Issues, 2007", EDUCAUSE Quarterly Magazine, Vol. 30, No. 3, pp. 15-22. http://connect.educause.edu/Library/EDUCAUSE+Quarterly/TopTenTeachingandL earning/44831 (accessed 15 December 2008).

Garrison, D.R. and Kanuka H. (2004), 'Blended learning: Uncovering its transformative potential in higher education', The Internet and Higher Education, Vol. 7, Issue 2, 2nd Quarter 2004, pp. 95-105.

http://www.sciencedirect.com/science/article/B6W4X-4CGMX783/2/f0f52711f3be52c39b4fea932a5dd1e5 (accessed 15 December 2008). ISSN 1096-7516, DOI: 10.1016/j.iheduc.2004.02.001

Harrington, P. and Sarmiento, T. (2008), 'Bridging the theory and practice divide in HE: SimVenture - A two year case study', paper presented at the Institute for Small Business \& Entrepreneurship Conference, 5-7 November, Belfast, N. Ireland, available at: http://www.simventure.co.uk/ISBEPaper.pdf (accessed 28th November 2008).

Hawkins, P. (1999). The art of building windmills - career tactics for the $21^{\text {st }}$ century, Graduate into Employment Unit, The University of Liverpool, Liverpool. ISBN-10: 0953598004

Kaplan, R.S. and Norton, D.P. (1992) 'The balanced scorecard: measures that drive performance', Harvard Business Review Jan - Feb pp. 71-80.

Loddington, S.P., Wilkinson, N., Glass, J. and Willmot, P. (2008) 'An Examination of Academic and Student Attitudes to the Peer Assessment of Group Work using WebPA in Engineering' presented at EE2008 - the International Conference on Innovation, Good Practice and Research in Engineering Education, 14-16 July 2008, Loughborough, UK available at:

http://www.engsc.ac.uk/downloads/scholarart/ee2008/p016-loddington.pdf (accessed 15 December 2008).

ISBN 9781904804659

Meyer, K.A. (2003). 'Face-to-face versus threaded discussions: The role of time and higher-order thinking', Journal of Asynchronous Learning Networks, Vol. 7, Issue 3, pp. 55-65.

ISSN 1092-8235 (online) ISSN 1939-5256 (print)

Nielsen, J. (2005), Ten usability heuristics, available at:

http://www.useit.com/papers/heuristic/heuristic list.html (accessed 15

December 2008).

ISSN 1548-5552

Oblinger, D. (2004) 'The Next Generation of Educational Engagement', Journal of Interactive Media in Education, 2004 (8), Special Issue on the Educational

Semantic Web, available at: http://www-jime.open.ac.uk/2004/8/oblinger-20048.pdf (accessed 15 December 2008).

ISSN $1365-893 X$ 
Peters, L.D. and Brodie, I. (2005). 'Using a business simulation game to foster teamwork and integrated decision-making', BEST Stories, The Higher Education Academy Business, Management and Accountancy Subject Centre.

ISBN 0749215356 